\title{
AVALIAÇÃO DA CONTAMINAÇÃO POR COBRE E CHUMBO DO LAGO ARATIMBÓ - UMUARAMA - PR
}

\author{
Bruna Gouveia Consalter ${ }^{1}$ \\ Danielle Mariano de Miranda ${ }^{2}$ \\ Jean Silva de Souza ${ }^{3}$ \\ Adriana Dias Martins Ferrarezi ${ }^{4}$ \\ José Gaspar Ferrarezi ${ }^{5}$ \\ Luciano Seraphim Gasques ${ }^{6}$
}

CONSALTER, B. G.; MIRANDA, D. M. de; SOUZA, J. S. de; FERRAREZI, A. D. M.; FERRAREZI, J. G.; GASQUES, L. S. Avaliação da contaminação por cobre e chumbo do lago Aratimbó - Umuarama - PR. Arq. Cienc. Saúde UNIPAR, Umuarama, v. 23, n. 2, p, 107112, maio/ago. 2019.

\begin{abstract}
RESUMO: Este trabalho teve como objetivo quantificar os metais Cobre e Chumbo presentes na água e no sedimento do lago Aratimbó, localizado na cidade de Umuarama-PR e analisar os indicadores abióticos de temperatura e pH da água. As coletas foram feitas em triplicatas, em três pontos distintos, em dois diferentes dias, sendo o primeiro em tempo seco, anterior a chuva e outro logo após a primeira chuva. As amostras tiveram sua temperatura e pH verificado in loco e a determinação dos metais ocorreu por meio de Espectrofotometria de Absorção Atômica por chama. Os resultados de pH obtiveram valores satisfatórios em todos os pontos. Em relação à concentração de metais, na água, houve maior concentração de chumbo antes da chuva e uma concentração abaixo do limite apenas para o cobre no ponto 1. No sedimento, a concentração de ambos metais foi maior antes da chuva, exceto no ponto três, onde a concentração foi maior após a chuva. É possível que os maiores valores de concentração para os metais tenham sido superiores no período de seca em virtude do volume aumentado de água após a chuva, com maior diluição. Assim, podendo atribuir a contaminação às atividades antropogênicas, uma vez que o lago se localiza em região urbana central.
\end{abstract}

PALAVRAS-CHAVE: Contaminação. Metais. Lago Aratimbó.

\section{EVALUATION OF COPPER AND LEAD CONTAMINATION OF THE ARATIMBÓ LAKE IN UMUARAMA - PARANÁ}

ABSTRACT: The purpose of this paper was to quantify the copper and lead present in the water and sediments of the Aratimbó lake, located in the city of Umuarama, in the state of Paraná, and to analyze the abiotic indicators of temperature and $\mathrm{pH}$ of the water. The samples were taken in triplicate at three different points, on two different days - the first during dry weather, before the rain, and the other after the first rain. The temperature and $\mathrm{pH}$ of the samples were verified in locu and the metals were determined through Atomic Absorption Spectrophotometry by flame. The $\mathrm{pH}$ results obtained satisfactory values at all points. Regarding the concentration of metals in the water, a higher concentration of lead was observed before the rain and a concentration below the limit was observed only for copper in point 1 . In the sediment, the concentration of both metals was higher before the rain, except in point three, where the concentration was also higher after the rain. It is possible that the highest concentration values for the metals were higher in the dry period due to the increased volume of water after rainfall, with higher dilution of the metals, as well as the attribution of contamination to the anthropogenic activities, since the lake is located in a central urban region.

KEYWORDS: Contamination. Metals. Lake Aratimbó.

\section{Introdução}

As questões de degradação ambiental tornaram-se um problema social de grande importância. As atividades humanas geram alterações no meio, que por sua vez podem resultar em poluição ou contaminação do meio ambiente, ocasionando assim o desequilíbrio. Entende-se por poluição quaisquer alterações físico-químicas ou biológicas causadas pelos poluentes, e que são responsáveis por interferir no ecossistema (MACEDO, 2002).

Lagos urbanos apresentam grande importância paisagística, além de proporcionar áreas representativas para serem utilizadas pela população para descanso e lazer em seu entorno. Além disso, frequentemente, os lagos urbanos geralmente estão inseridos em áreas de preservação e podem servir como refúgios para animais apesar de estarem localizados em grandes adensamentos urbanos (NABOUT; NOGUEIRA, 2011). Ao mesmo tempo em que se mostram essenciais para o espaço urbano, também são afetados drasticamente pela ação antrópica ao seu redor, problemas ambientais decorrentes principalmente dos avanços demográficos e das atividades econômicas desenvolvidas em seu entorno (TUCCI; SANT'ANNA, 2003; OBERHOLSTER et al., 2006).

A Resolução CONAMA no $357 / 05$, dispõe sobre a classificação e diretrizes ambientais para o enquadramento dos corpos de águas superficiais, bem como estabelece as condições e padrões de lançamento de efluentes. Segundo essa resolução, as águas são classificadas em doces, salinas e salobras, sendo a água doce classificada em Classe Especial, Classe 1, 2, 3 e 4.

O Lago Aratimbó, (2345'17.4”S 53¹7'15.4'W) classificado como lago de água doce Classe 3, é um exemplo de lago urbano que vem sofrendo pressão antrópica, indicando desequilíbrios ambientais, a ponto inclusive de despertar o interesse do Conselho Municipal do Meio Ambiente em avaliar alguns indicadores ambientais do mesmo (CMMA,

DOI: 10.25110 /arqsaude.v23i2.2019.6871

${ }^{1}$ Egressa do Curso de Química Industrial, Universidade Paranaense - UNIPAR, Umuarama - PR. E-mail: danimmiranda@hotmail.com

${ }^{2}$ Egressa do Curso de Química Industrial, Universidade Paranaense - UNIPAR, Umuarama - PR

${ }^{3}$ Discente do Curso de Química Industrial, PIBIC, Universidade Paranaense - UNIPAR, Umuarama - PR. E-mail: jea.souza@edu.unipar.br

${ }^{4}$ Docente do Curso de Química Industrial e Farmácia, Universidade Paranaense - UNIPAR, Umuarama - PR. E-mail: adridias@prof.unipar.br

${ }^{5}$ Docente do Curso de Química Industrial, Universidade Paranaense - UNIPAR, Umuarama - PR. E-mail: gaspar@prof.unipar.br

${ }^{6}$ Docente do Curso de Medicina e Nutrição, Universidade Paranaense - UNIPAR, Umuarama - PR. E-mail: 1sgasques@prof.unipar.br 
2016).

No meio aquático, os metais são oriundos de fontes naturais como lavagem geológica de solos e rochas diretamente expostos à água, de fontes antrópicas (como por exemplo, efluentes domésticos, industriais e resíduos), de processo de mineração, de aplicação de pesticidas na agricultura (EBRAHIMPOUR \& MUSHRIFAH, 2008) e através de precipitação em áreas com poluição atmosférica (PEREIRA, 2004). Assim, muitas vezes a contaminação pode comprometer a qualidade das águas superficiais e subterrâneas, afetando a saúde de espécies animais e vegetais, e do próprio homem.

Nos ecossistemas aquáticos, os metais e outros compostos tendem a acumular no sedimento (SHRIVASTAVA et al., 2003) e, dependendo das condições ambientais, podem começar a ser liberados na coluna d'água tornando-se biodisponíveis. Nessas condições, podem afetar a biota, sendo incorporados ao longo da cadeia alimentar e, consequentemente, podendo causar danos também à saúde humana (KHAN et al., 2005). Este fato é comum ao lago Aratimbó, que embora, tenha uma proibição expressa de pesca, é possível verificar frequentemente pessoas pescando com finalidade de alimentação.

Os metais são contaminantes ambientais estáveis e persistentes, uma vez que não podem ser degradados ou destruídos (SILVA, 2016). Quando liberados na água, são adsorvidos, a princípio em partículas orgânicas ou inorgânicas, e só depois depositados no sedimento. Dessa forma, é normal encontrar maior concentração de metais nos sedimentos que na água.

Para os seres humanos a contaminação por certos metais pode levar a graves complicações de saúde. A exposição às altas concentrações de cobre pode levar à disfunção intestinal, náuseas, vômitos e dor abdominal. Em caso de superexposição há o risco de desenvolver câncer de pulmão e estômago. $\mathrm{O}$ limite da concentração de cobre que pode ser ingerido, segundo a legislação brasileira, é de $5 \mathrm{mg} . \mathrm{L}^{-1}$ (MACEDO, 2002).

Com relação à contaminação ambiental causada por chumbo é preciso considerar sua extrema toxicidade e penetrância. $\mathrm{O}$ chumbo se acumula no cérebro humano causando uma série de problemas, desde a cegueira, paralisia e até a morte, e em crianças os danos cerebrais normalmente são irreversíveis. Em adultos, o plumbismo ocorre por questões ocupacionais. Níveis superiores à $0,005 \mathrm{mg} . \mathrm{L}^{-1}$ no sangue ou $0,008 \mathrm{mg} . \mathrm{L}^{-1}$ na urina indicam envenenamento (MACEDO, 2002).

Dentre os organismos aquáticos, os peixes têm se destacado em vários estudos em relação à contaminação por metais pesados - metais altamente reativos e bioacumulativos, dentre eles, o cobre e o chumbo - pois possuem capacidade de acumular metais essenciais e não-essenciais no seu tecido muscular. Com o seu alto índice proteico, o peixe tem se tornado essencial na alimentação do homem, tornando-se, uma das principais fontes de ingestão de metais para o homem (LIMA et al, 2013). Como resultado, alguns metais presentes em tais seres vivos são transferidos para os seres humanos através da alimentação e os acumula em seu organismo. Pequenas quantidades de alguns metais como, cobalto, cobre, manganês, molibdênio, vanádio, estrôncio e zinco, são essenciais para o funcionamento do organismo dos seres vivos, contudo, esses elementos tornam-se tóxicos em altos níveis. Todavia, alguns elementos, no qual o chumbo é um exemplo, não possuem nenhuma função no organismo e resultam em doenças quando acumulados em mamíferos (FERREIRA; HORTA; CUNHA, 2010).

Desse modo, é de grande importância a realização de estudos para a avaliação da qualidade, de lagos urbanos visando a esclarecer os níveis de metais pesados e outros indicadores abióticos. O objetivo do presente estudo foi quantificar os metais cobre e chumbo presentes na água e sedimento do Lago Aratimbó, assim como, averiguar os indicadores abióticos de $\mathrm{pH}$ e temperatura da água.

\section{Material e Método}

\section{Caracterização do ambiente e coleta das amostras}

O Lago Aratimbó está localizado na cidade de Umuarama - PR, que segundo o IBGE de 2010, possui uma população de 100676 habitantes (IBGE, 2010). O lago artificial foi entregue à população em 31 de dezembro de 2000. Possui uma área aproximada de $30000 \mathrm{~m}^{2}$ e está regulamentado pelo Decreto Municipal no 080/99 (EIA-COPOL, 1999). Teve sua construção com os objetivos principais de paisagismo e lazer para a população local, e consequentemente a valorização de loteamentos ao seu entorno.

As amostras de água e sedimentos foram coletadas, em triplicata, em três pontos diferentes do Lago Municipal (Fig. 1), na margem direita P1.1 (23045'16.8”'S $\left.53^{\circ} 17^{\prime} 13.6^{\prime \prime} \mathrm{W}\right), \quad \mathrm{P} 1.2 \quad\left(23^{\circ} 45^{\prime} 16.5^{\prime \prime} \mathrm{S} \quad 53^{\circ} 17^{\prime} 14.3^{\prime \prime} \mathrm{W}\right)$,

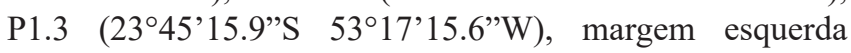

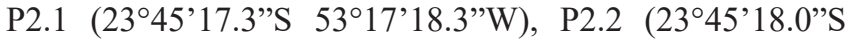

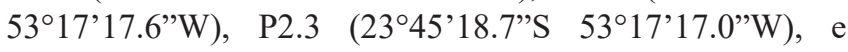

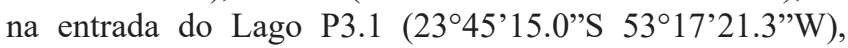

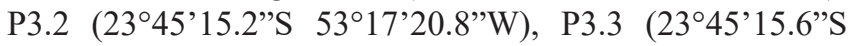
$\left.53^{\circ} 17^{\prime} 20.2^{\prime \prime} \mathrm{W}\right)$, em dois momentos distintos, $a$ primeira coleta feita no dia 27 de setembro de 2016, às 14:30 em período de estiagem de 8 dias e a segunda coleta feita no dia 03 de outubro de 2016, às 13:30, em dia de chuva, em que o índice pluviométrico foi de $26 \mathrm{~mm}$, após 14 dias de estiagem. Os fatores abióticos foram avaliados in loco e as amostras foram acondicionadas em frascos plásticos e conservadas na geladeira até o momento da abertura das mesmas.

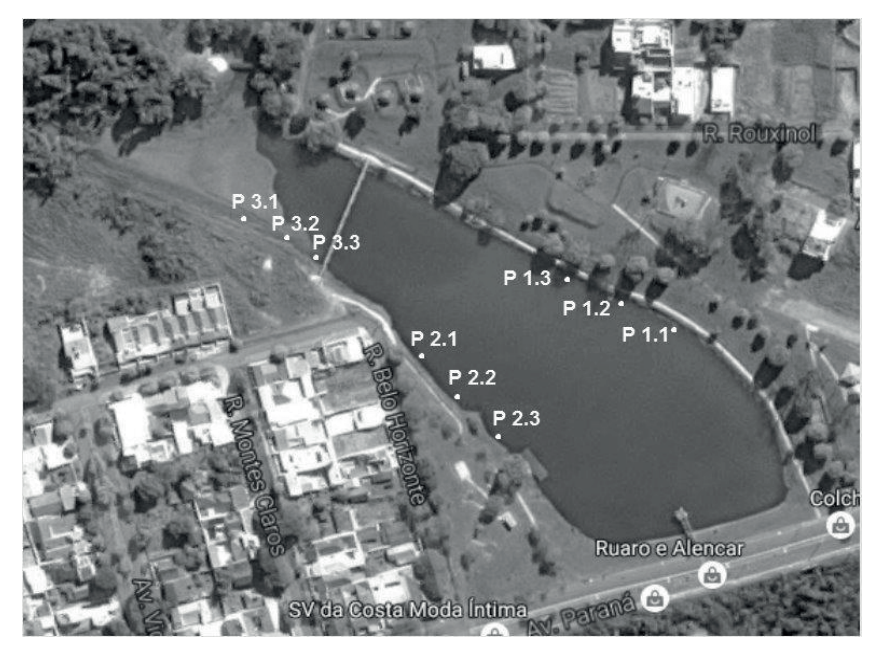

Figura 1: Lago Aratimbó. P mostra a posição dos Pontos de Coleta. A imagem é adaptada do Google Maps. 


\section{Análise dos fatores Abióticos}

Cada ponto de coleta teve a temperatura da água averiguada em termômetro analógico do tipo $-10{ }^{\circ} \mathrm{C}$ a 100 ${ }^{\circ} \mathrm{C}$ (bulbo de mercúrio) e o $\mathrm{pH}$ determinado por meio de fita indicadora de $\mathrm{pH}$ (Macherey - Nagel pH Fix 0-14).

\section{Determinação de Metais pesados}

\section{Preparação das Amostras}

Antes de iniciar a preparação das amostras, as vidrarias foram todas lavadas em água corrente e com detergente, em seguida colocadas de molho por 24 horas em solução de $\mathrm{HNO}_{3}$ a $20 \%$. Após esse período, foram enxaguadas com água deionizada e colocadas para secar conforme descrito em Apha (1998).

\section{Amostras de Sedimento}

As amostras de sedimento foram retiradas da geladeira, onde permaneceram desde a coleta, e levadas ao laboratório para ser feita a secagem. Foi colocado aproximadamente $100 \mathrm{~g}$ do sedimento em uma cápsula de porcelana, e colocado em estufa a $60{ }^{\circ} \mathrm{C}$ por 48 horas. Após esse período, a amostra foi retirada da estufa e colocada para resfriar em dessecador, até atingir a temperatura ambiente.

A seguir, tendo como base a metodologia de Forstner (2003), foi preparada uma solução de $\mathrm{HCl}$ e $\mathrm{HNO}_{3}$, numa proporção de $3: 1$, conhecida como água régia.

Para a digestão das amostras adicionou-se $10 \mathrm{~mL}$ da solução de Forstner a uma massa de aproximadamente $1,0000 \mathrm{~g}$ de sedimentos que permaneceu em repouso no béquer tampado com vidro de relógio por 16 horas. Após este período, as amostras foram aquecidas em banho-maria a 90 ${ }^{\circ} \mathrm{C}\left(+/-5^{\circ} \mathrm{C}\right)$, por duas horas, com o béquer parcialmente tampado. Esse procedimento foi realizado para todas as amostras.

Depois de 2 horas de aquecimento as amostras foram filtradas em papel filtro, transferidas e avolumadas em balão volumétrico de $100 \mathrm{~mL}$ e, posteriormente, acondicionadas em frascos e mantidas a $4^{\circ} \mathrm{C}$ até o momento da leitura.

Após a preparação das amostras de sedimento as vidrarias utilizadas foram lavadas e colocadas de molho em solução de $\mathrm{HNO}_{3}$, por 24 horas, como descrito anteriormente.

\section{Amostras de Água}

As amostras de água foram preparadas seguindo a metodologia Apha (1995), digerindo-se uma alíquota de 100 $\mathrm{mL}$ com $5 \mathrm{~mL}$ de ácido nítrico concentrado e levadas para a chapa de aquecimento, para solubilização dos elementos de interesse, sendo evaporadas em ebulição suave até obtenção de um volume de cerca de $20 \mathrm{~mL}$, aproximadamente durante 2 a 3 horas. Após esse período, as amostras foram filtradas, e a seguir avolumadas novamente a $100 \mathrm{~mL}$ em balão volumétrico e transferidas para frascos e mantidas a $4{ }^{\circ} \mathrm{C}$ até o momento da leitura.

\section{Análise para determinação de Metais}

As leituras das amostras foram realizadas em Espectrofotômetro de Absorção Atômica por Chama, GBC 932 Plus. Inicialmente o aparelho foi calibrado, em seguida realizada a curva de calibração utilizando a solução padrão de Cobre, nas concentrações de $0,1 \mathrm{mg} / \mathrm{L}$ a $3,0 \mathrm{mg} / \mathrm{L}$, apresentando um coeficiente de regressão linear superior a 0,997 , e feita leitura da absorbância das amostras de água e sedimentos. Na sequência foi efetuada uma curva de calibração utilizando a solução padrão de Chumbo, nas concentrações de $0,3 \mathrm{mg} / \mathrm{L}$ a 4,0 mg/L, apresentando um coeficiente de regressão linear superior a 0,999 e feita leitura da absorbância das amostras de água e sedimentos.

\section{Resultados e Discussão}

Com relação aos indicadores abióticos de temperatura e $\mathrm{pH}$ da água do Lago Aratimbó, os resultados encontram-se dispostos na Tabela 1.

Tabela 1: Média por Ponto de Coleta dos Indicadores Abióticos

\begin{tabular}{c|cc|cc}
\hline \multicolumn{5}{c}{ INDICADORES ABIÓTICOS } \\
\hline \multicolumn{3}{c}{ pH } & \multicolumn{2}{c}{ TEMPERATURA ${ }^{\circ} \mathrm{C}$} \\
\hline PONTOS DE & ANTES DA & DURANTE A & ANTES DA & DURANTE A \\
COLETA & CHUVA & CHUVA & CHUVA & CHUVA \\
1 & 7,7 & 7,2 & 29,5 & 22,3 \\
2 & 7,0 & 7,5 & 29,7 & 22,0 \\
3 & 6,5 & 7,0 & 29,7 & 21,0 \\
\hline
\end{tabular}

As variações de temperatura são resultados do clima, tempo, latitude, altitude, período do dia, estações do ano e profundidade. Com relação à variação do $\mathrm{pH}$, os valores encontrados obedecem às condições dispostas pelo CONAMA na Resolução no 357/05. O lago Aratimbó, segundo a resolução, é classificado como água doce de Classe 3 e, portanto, o pH da água deve ser entre 6,0 e 9,0.

Conceição et al. (2015) avaliando cinco pontos do lago Aratimbó nos meses de abril e maio de 2009 também obtiveram valores de $\mathrm{pH}$ e temperatura semelhantes aos encontrados na presente pesquisa. Porém, os valores de sua pesquisa, de coleta realizada no mês de junho, mostraram valores de temperaturas variando de $15,90{ }^{\circ} \mathrm{C}$ à $16,50{ }^{\circ} \mathrm{C}$. A baixa temperatura no mês de junho deve-se a proximidade do inverno no qual a temperatura média do lago tende a sofrer redução.

As análises das amostras de água do lago determinaram as concentrações de metais que foram relacionadas nas Figura 2 e Figura 3 a seguir. 


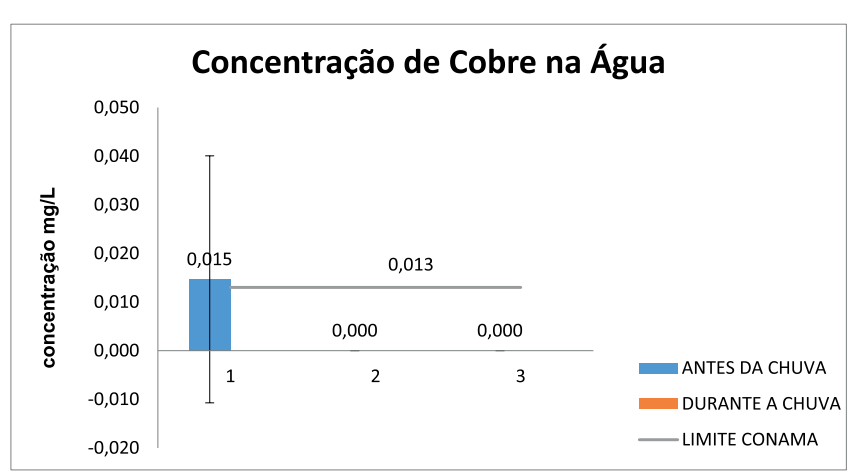

Figura 2: Média das concentrações de cobre na água do lago por ponto de coleta.

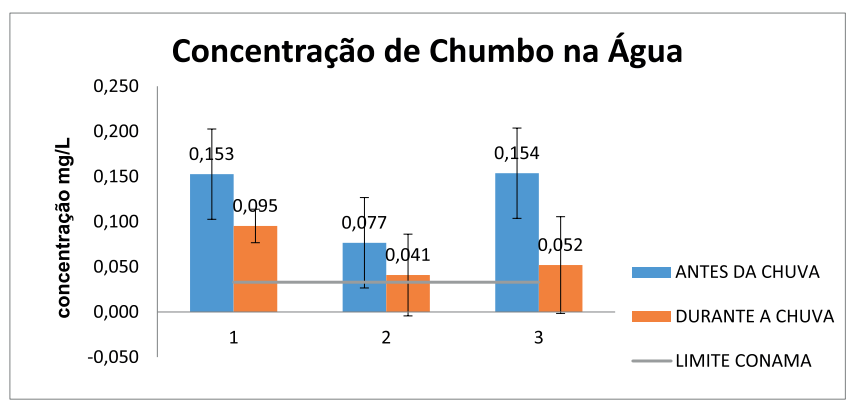

Figura 3: Média das concentrações de chumbo na água do lago por ponto de coleta.

Considerando os limites de concentração para o elemento cobre, em corpos de água doce, preconizados pelo CONAMA em lagos Classe 3 ser de 0,013 mg/L quando comparado com os valores encontrados, verifica-se que o lago obteve alteração em relação a esse metal. A concentração de cobre na água ficou acima do limite no ponto 1 de coleta antes da chuva, e durante a chuva a concentração diminuiu, devido à diluição sofrida pela água da chuva. A concentração de metais na água pode ser explicada pela localização urbana central e a atividades humanas na bacia tributária (CAETANO; MARTINS; MERLINI, 2011). Na região da bacia tributária são encontradas estradas e ruas de grande movimentação de veículos e sendo ainda bastante urbanizada, principalmente com comércios e casas.

A concentração encontrada de chumbo na água também ficou acima do limite do CONAMA em todos os pontos de coleta. Essa concentração de metais maior antes da chuva leva a entender que em períodos sem chuva os metais se concentram devido à diminuição do volume de água no lago.

O chumbo é facilmente introduzido no ecossistema aquático por meio de processos e produtos humanos - plásticos, tintas, pigmentos, aditivos de gasolina - pois este metal geralmente é utilizado em construções civis, munições, baterias ácidas, é também um dos constituintes das ligas metálicas para a produção de soldas, revestimentos de cabos elétricos e entre outros (ROCHA, 2009).

Em contraste aos nossos resultados, o estudo realizado por Lima (2013), na Bacia do Rio Cassiporé, verificou que a sazonalidade provoca variações nas concentrações de metais na água de maneiras peculiares, tendo maior influência sobre as concentrações de $\mathrm{Cu}$ e $\mathrm{Pb}$, onde as maiores concentrações de metais são encontradas no período chuvoso, resultantes das fontes e ações antropogênicas que norteiam os cursos d'água, especialmente a atividade garimpeira.

Vaz et al. (1997), estudando a dinâmica do cobre no lago do Parque do Ingá - Maringá-PR, encontraram diversos valores de concentração de cobre nos locais que foram realizadas a amostragem, tanto na água como em sedimentos, podendo ter a possibilidade da migração de cobre para a água e ocorrendo uma maior concentração do elemento.

Nos estudos realizados por Caetano et al. (2011), no Lago Aratimbó, pode-se notar que a concentração de cobre e chumbo não foi detectada em nenhum dos pontos de coletas de água, porém foi encontrado cobre nas vísceras dos peixes coletados. Se no estudo em questão os níveis de cobre e chumbo não foram detectados na água e já foram detectados em vísceras de peixes, e agora os resultados encontrados na água apresentam-se superiores aos limites estabelecidos, pode-se sugerir que a contaminação dos peixes seja maior. Este fato é plausível quando analisado a luz da cadeia alimentar.

Nas Figuras 4 e 5 são apresentadas as médias das concentrações de metais encontrados nas análises de sedimento.

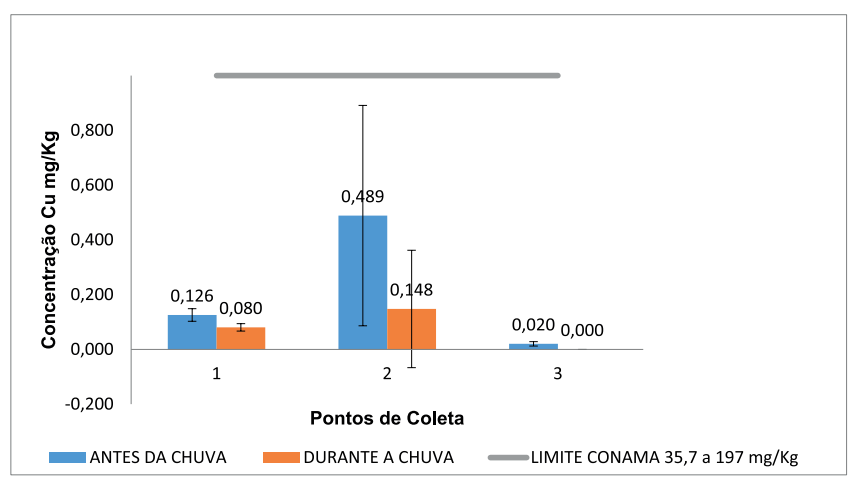

Figura 4: Média das concentrações de cobre no sedimento do lago Aratimbó por ponto de coleta.

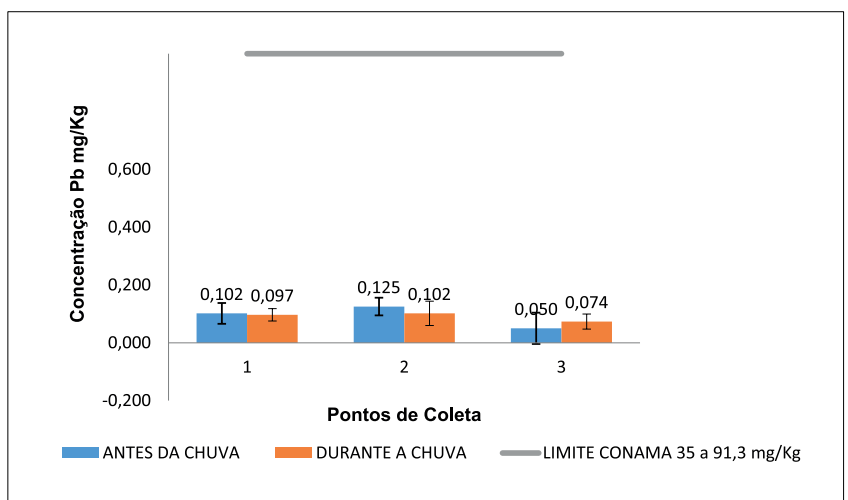

Figura 5: Média das Concentrações de Chumbo no Sedimento do Lago Aratimbó por ponto de coleta.

Em relação ao sedimento, as concentrações de cobre e chumbo foram maiores no período antes da chuva, exceto para chumbo no ponto 3 , onde a concentração foi maior durante a chuva. Porém, em todos os pontos de coleta, as concentrações ficaram abaixo dos limites estabelecidos pela Resolução n ${ }^{\circ}$ 344/04 do CONAMA. Esses resultados comprovam que os metais se acumulam mais no sedimento do que na água.

Segundo estudo realizado por Quináglia (2006), a biodisponibilidade do cobre é influenciada por processos de 
complexação de ligantes orgânicos e inorgânicos, adsorção a óxidos metálicos, argila e material particulado em suspensão e troca entre sedimento e água. O chumbo encontra-se na água proveniente de emissões atmosféricas, lixiviação do solo, de fontes antrópicas.

Cotta et al. (2006) em estudo realizado no sedimento do rio Betari, mostra que metais acumulados nos sedimentos de lagos e rios podem sofrer alteração de sua biodisponibilidade através de mudanças nas condições ambientais. Uma vez sedimentados esses metais podem ser novamente redisponibilizados para a coluna d'água, graças a reações de oxirredução ou a processos de resuspensão de origem física (correnteza), biológica (atividade dos organismos que vivem nos sedimentos) e humana (dragagem e navegação).

Caetano et al. (2011) relatam que as variações de cobre e chumbo nos sedimentos do lago Aratimbó devem ser resultado de ação antropogênica. Portanto, monitorar a qualidade da água é importante para saúde do cidadão, assim como os dados nutricionais do pescado daquela região que pode ter a presença de metais pesados.

A existência de tubulações de esgotos ligados clandestinamente às cinco galerias de águas pluviais que desembocam no lago, vem acarretando o aumento de matéria orgânica e substâncias químicas, contaminando o corpo d'água. Outro fator de contaminação é a ausência de mata ciliar nas margens do lago, ocasionando o transporte de sedimentos para o lago, assoreando-o.

\section{Conclusão}

Com base nos resultados obtidos nas análises da água e do sedimento do lago Aratimbó, pode-se concluir que as concentrações de metais no sedimento estão abaixo do limite da legislação vigente, porém, a concentração de cobre e chumbo na água estão acima do limite.

Considerando que houve um aumento da concentração de cobre e chumbo na água do Lago Aratimbó em relação a 2006, devem-se realizar estudos mais aprofundados na biota do lago, uma vez que muitas pessoas pescam no local e utilizam estes peixes na alimentação. Como a concentração destes metais nos peixes é cumulativa e associada à cadeia alimentar, deve haver um aumento destes valores presentes nos peixes. Dessa forma, é possível que a ingestão destes peixes ocasione sérios problemas de saúde devido ao acúmulo desses metais no organismo humano.

\section{Referências}

AMERICAN PUBLIC HEALTH ASSOCIATION. Part 3000, Metals. In: Standard Methods for the Examination of Water and Wastewater, 19 ed., p. 3.1 -3.106, 1995.

\section{AMERICAN PUBLIC HEALTH ASSOCIATION} (APHA), Standard Methods for the Examination of Water and Wastewater. American Water Works Association, Water Environmental Federation. 20. ed., Washington 1998.

CAETANO, I. C. S. da; MARTINS, L. A. de; MERLINI, L. S. Análise da qualidade da água e dos peixes do lago Aratimbó, Umuarama PR - Brasil. Arq. Ciênc. Saúde UNIPAR, Umuarama, v. 15, n. 2, p. 149-157, maio/ago. 2011.
CONCEIÇÃO, V. M.; OLIVEIRA, R. B.; PEIXOTO, L. S.; BATISTELA, V. R. Estudo do efeito da urbanização da água do Lago Municipal Aratimbó em Umuarama, Paraná. Disponível em: http:/www.ambiente-augm.ufscar.br/ uploads/A2-074.pdf. Acesso em: 17 abr. 2018

CONSELHO MUNICIPAL DE MEIO AMBIENTE, Umuarama, Ata $n^{0}$ 100/2016 da Reunião do Conselho Municipal de Meio Ambiente realizada no dia 28 de março de 2016.

COMISSÃO NACIONAL DO MEIO AMBIENTE Resolução CONAMA no 357. Diário Oficial da União, Brasília, DF, Brasil. 2005.

COMISSÃO NACIONAL DO MEIO AMBIENTE Resolução CONAMA no 344. Diário Oficial da União, Brasília, DF, Brasil. 2004.

COTTA, J. A. O.; REZENDE, M. O. O; PIOVANI, M. R. Avaliação do Teor de Metais em Sedimentos do Rio Betari no Parque Estadual Turístico do Alto Ribeira - PETAR, São Paulo, Brasil. Química Nova, v. 29, n. 1, p. 40-45, 2006.

EBRAHIMPOUR, M. \& MUSHRIFAH, I. Heavy metal concentrations $(\mathrm{Cd}, \mathrm{Cu}$ and $\mathrm{Pb})$ in five aquatic plant species in Tasik Chini, Malaysia. Environ Geol. v. 54, p. 689-698. 2008.

EIA - COPOL. Estudo de impacto ambiental: lago municipal Aratimbó. Construtora Oshima de Projetos e Obras, 1999.

FERREIRA, A. P.; HORTA, M. A. P.; CUNHA, C. L. N. Avaliação das concentrações de metais pesados no sedimento, na água e nos órgãos de Nycticorax nycticorax (Garça-da-noite) na Baía de Sepetiba, Rj, Brasil. Gestão Costeira Integrada, v. 10, n. 2, p. 229-241, 2010.

FÖRSTNER, U. Geochemical techniques on contaminated sediments - river basin view. PartI: Integrated water quality management: river basin approach. Environ. Sci. \& Pollut. Res. v. 10, n. 1, p. 58-62, 2003.

IBGE. Umuarama - População. Disponível em: https:// cidades.ibge.gov.br/brasil/pr/umuarama/panorama. Acesso em: 17 jan. 2019.

KHAN, R.; ISRAILI, S.H.; AHMAD, H. \& MOHAN, A. Heavy Metal Pollution Assessment in Surface Water Bodies and its Suitability for Irrigation around the Neyevli Lignite Mines and Associated Industrial Complex, Tamil Nadu, India. Mine Water and the Environmentv. v. 24, p. 155161. 2005.

LIMA, D. Avaliação da contaminação por metais pesados na água e nos peixes da bacia do rio Cassiporé, Estado do Amapá, Amazônia, Brasil. 2013, 147f. Dissertação (Mestrado em Biodiversidade Tropical), Universidade Federal do Amapá, Amapá, 2013. 
MACEDO, J. A. B. de. Introdução à Química Ambiental (Química \& Meio Ambiente \& Sociedade). Editora SRQ, 1. ed. MG, 2002.

NABOUT, J. C.; NOGUEIRA, I. S. Variação temporal da comunidade fitoplanctônica em lagos urbanos eutróficos. Acta Scientiarum. Biological Sciences, Maringá, v. 33, n. 4, p. 383-391, 2011.

OBERHOLSTER, P. J.; BOTHA, A. M.; ClOETE, T. E. Toxic cyanobacterial blooms in a shallow, artificially mixed urban lake in Colorado, USA. Lakes and Reservoir: Research and Management, v. 11, n. 2, p. 111-123, 2006.

PEREIRA, R. S. Identificação e caracterização das fontes de poluição em Sistemas Hídricos. ReRH. v. 1, n. 1. p. 20-36, jul/set, 2004.

QUINÁGLIA, G. A. Caracterização dos níveis basais de concentração dos metais nos sedimentos no sistema estuarino da baixada Santista. 2006, 269 f. Tese (Doutorado), Universidade de São Paulo, São Paulo, 2006.

ROCHA, A. F. Cádmio, Chumbo, Mercúrio - A problemática destes metais pesados na Saúde Pública. 2009, 63 f, Monografia (Trabalho de Conclusão de Curso), Faculdade de Ciências da Nutrição e Alimentação, Porto, 2009.

SHRIVASTAVA, P.; SAXENA, A.; SWARUP, A. Heavy metal pollution in a sewagefed lake of Bhopal, (M. P.) India. Lakes \& Reservoirs: Research and Management, v. 8, p. 1-4. 2003.

SILVA, S. C. Metais no meio ambiente aquático. Portal de Ecologia Aquática. São Paulo, Disponível em: http://ecologia.ib.usp.br/portal/index.php?view=a rticle\&catid $=9 \% 3$ Aecolimno\& $\mathrm{id}=125 \% 3$ Ametais-nomeio-ambiente-aquatico \& format $=$ pdf\&option $=$ com content\&Itemid=312\#referencias. Acesso em: 25 jul. 2016.

TUCCI, A.; SANT'ANNA, C. L. Cylindrospermopsis raciborskii (Woloszynska) Seenayya e Subba Raju (Cyanobacteria): variação semanal e relações com fatores ambientais em um reservatório eutrófico. Rev. Bras. Bot., São Paulo, v. 26, n. 1, p. 97-112, 2003.

VAZ, S. R.; LENZI, E.; LUCHESE, E. B.; FÁVERO, L. O. B. Dinâmica do cobre no lago Parque do Ingá, Maringá - PR. UNIMAR, Maringá, v. 19, n. 4, p. 1055-1067, 1997. 